\title{
Classificação da precipitação pluviométrica anual para o município de Parnamirim - PE utilizando Índice de Anomalia de Chuva (IAC)
}

\author{
Classification of annual rainfall for the municipality of Parnamirim - PE using Rain \\ Anomaly Index (IAC)
}

\section{RODRIGUES, Adriana de Carvalho Figueiredo. Doutorado/Engenharia Agrícola}

Instituto Federal do Sertão Pernambucano - Campus Salgueiro. BR 232, Km 504, sentido Recife, Zona Rural Salgueiro - PE - Brasil. CEP: 56.000-000 / Telefone: (87) 98119.2921 / E-mail: adriana.figueiredo@ifsertaope.edu.br

\section{RODRIGUES, Eriverton da Silva. Mestrado/Física}

Instituto Federal do Sertão Pernambucano - Campus Salgueiro. BR 232, Km 504, sentido Recife, Zona Rural Salgueiro - PE - Brasil. CEP: 56.000-000 / Telefone: (87) 98119.2921 / E-mail: eriverton.rodrigues@ifsertaope.edu.br

\section{SILVA, Carlos Wendel Gomes da. Técnico/Edificações}

Instituto Federal do Sertão Pernambucano - Campus Salgueiro. BR 232, Km 504, sentido Recife, Zona Rural Salgueiro - PE - Brasil. CEP: 56.000-000 / Telefone: (87) 98119.2921 / E-mail: cwendel1@hotmail.com

\section{GALVÃO, Sandra Regina da Silva. Doutorado/Tecnologias Energéticas Nucleares}

Instituto Federal do Sertão Pernambucano - Campus Salgueiro. BR 232, Km 504, sentido Recife, Zona Rural Salgueiro - PE - Brasil. CEP: 56.000-000 / Telefone: (87) 98119.2921 / E-mail: sandra.galvao@ifsertao-pe.edu.br

\section{RESUMO}

0 trabalho teve como objetivo avaliar o comportamento da variabilidade das precipitações anuais utilizando o Índice de Anomalia de Chuva (IAC) para dados pluviométricos obtidos na Agência Pernambucana de Água e Clima (APAC), referentes ao município de Parnamirim-PE, localizado na região semiárida do Sertão Central Pernambucano. Para o desenvolvimento do estudo utilizou-se duas séries históricas precipitação pluvial que corresponderam aos períodos de 1919 a 1978 e 1994 a 2019, disponibilizados pela APAC. Os dados foram utilizados para calcular os IACs positivos e negativos para classificação de extremos. No período de dezembro a abril se encontram as maiores contribuições de chuvas para o município, o que corresponde a aproximadamente $81 \%$ e $82 \%$ das chuvas anuais das respectivas séries. Entre os meses de maio a novembro verificam-se as menores chuvas locais, compreendendo assim, ao período de estiagem. Com os resultados obtidos, verificou-se que o município de Parnamirim possui uma pluviosidade extremamente irregular, sendo a variabilidade da precipitação a principal característica do regime de chuvas na região do sertão pernambucano.

Palavras-chave: Índice de Anomalia de Chuva; Semiárido; Estiagem.

\section{ABSTRACT}

The objective of this work was to evaluate the behavior of annual rainfall variability using the Rain Anomaly Index (IAC) for pluviometric data obtained at the Pernambuco Water and Climate Agency (APAC), referring to the municipality of Parnamirim-PE, located in the semiarid region do Sertão Central Pernambucano. For the development of the study, two historical series of rainfall were used, corresponding to the periods from 1919 to 1978 and 1994 to 2019, provided by APAC. The data were used to calculate the positive and negative IACs for classification of extremes. In the period from December to April there are the largest contributions of rain to the municipality, which corresponds to approximately $81 \%$ and $82 \%$ of the annual rainfall of the respective series. Between the months of May and November there are the lowest local rains, thus comprising the drought period. With the 
RODRIGUES, ACF; RODRIGUES, ESR; SILVA, CWG; GALVÃO, SRS

Classificação da precipitação pluviométrica anual para o município de Parnamirim - PE utilizando Índice de Anomalia de Chuva (IAC)

results obtained, it was found that the municipality of Parnamirim has an extremely irregular rainfall, with the variability of precipitation being the main characteristic of the rain regime in the region of the sertão pernambucano.

keywords: Rain Anomaly Index; Semi-arid; Drought.

\section{Introdução}

O Brasil possui uma grande extensão territorial e em virtude disto apresenta diferenciados regimes de precipitação, em escala regional e sub-regional. A grande diversidade de regimes pluviométricos existente no Nordeste do Brasil é consequência de vários fatores que atuam isoladamente ou em conjunto, determinando as condições climáticas da região (SANTOS et al., 2016). Esta diversidade é observada em cidades do interior do Nordeste, como é o caso da cidade de Parnamirim-PE, que está localizada numa região semiárida com precipitação pluvial irregular, tanto espacial quanto temporalmente.

A precipitação pluviométrica constitui, entre os elementos atmosféricos, o que apresenta maior interesse da sociedade. 0 conhecimento do comportamento da precipitação pluviométrica ao longo do tempo é imprescindível para o monitoramento dos impactos causados pelo excesso ou pela falta prolongada de chuva e contribui para o desenvolvimento de uma série de atividades, tanto nas áreas urbanas, quanto nas rurais (SPECIAN e VECCHIA, 2014; NUNES et al., 2016).

As secas registradas no Nordeste do Brasil é uma característica natural do clima e sua recorrência é inevitável. A durabilidade e intensidade deste fenômeno sofre influência tanto de fenômenos climáticos, quanto de sistemas em escala regional e local. Baixos índices de precipitação afetam diretamente a sociedade podendo causar elevados impactos negativos, como deficiência no fornecimento de água para abastecimento urbano e perdas na agricultura (GURJÃO et al., 2012).

Com base na precipitação irregular faz-se necessário o monitoramento através do emprego de índices climáticos. Com base neles, pode-se desenvolver um sistema de acompanhamento das características dos períodos de estiagem ou de chuva, com informações anuais, sazonais ou mensais, com as quais pode-se conhecer profundamente a climatologia de uma região, e verificar os impactos que o clima global causa sobre a distribuição pluviométrica local, ou seja, a regionalização da precipitação para determinado local (ARAÚJO et al., 2009(a)).

0 monitoramento de eventos hidrológicos extremos e a análise da variabilidade espaçotemporal da precipitação são importantes no gerenciamento de recursos naturais em regiões com fortes limitações hídricas como o semiárido brasileiro. A manutenção de projetos de irrigação implantados ao longo dos principais rios de abastecimento d'água nas grandes cidades e do monitoramento do nível dos reservatórios das hidrelétricas constitui aspectos fundamentais para o desenvolvimento regional e requer o uso de indicadores climáticos que auxiliem na conservação destes empreendimentos de forma sustentável (GURJÃO et al., 2012).

O Índice de Anomalias de Chuva (IAC) avalia o grau de severidade e duração de anos secos e chuvosos e sua intensidade, por meio da frequência com que ocorrem, tornando-se um método de estudar a precipitação pluviométrica avaliando anos de seca e chuva excessiva. 
RODRIGUES, ACF; RODRIGUES, ESR; SILVA, CWG; GALVÃO, SRS Classificação da precipitação pluviométrica anual para o município de Parnamirim - PE utilizando Índice de Anomalia de Chuva (IAC)

Por estar localizado na mesorregião do Sertão Pernambucano, região semiárida, o município de Parnamirim é caracterizado por baixos índices pluviométricos anuais e grande variabilidade espacial e temporal das chuvas (ALVES et al, 2016).

Nesse sentido, objetivou-se avaliar o comportamento da variabilidade das precipitações pluviométricas do município de Parnamirim-PE, utilizando o Índice de Anomalias de Chuvas para períodos de 60 e 26 anos de dados de chuvas na cidade de Parnamirim-PE, visando a avaliação dos seus padrões de distribuição. Assim o IAC segue tendências anuais, onde estimativas desta ordem podem ser realizadas com base em dados históricos.

\section{Material e métodos}

A região Nordeste está localizada aproximadamente entre $01^{\circ} \mathrm{S}$ e $18^{\circ} \mathrm{S}$ e $35^{\circ} \mathrm{W}$ a $47^{\circ} \mathrm{W}$. Sob ponto de vista climático, pode ser caracterizada por temperaturas elevadas o ano inteiro contrastando com a grande variabilidade espacial e temporal das chuvas (XAVIER e DORNELLAS, 2005).

O município de Parnamirim está inserido na região do sertão pernambucano, compreendendo uma área de $2.478 \mathrm{Km}^{2}$. Localizado entre as coordenadas geográficas de $8^{\circ} 04^{\prime} 30^{\prime \prime}$ de latitude sul e $39^{\circ} 07^{\prime} 30^{\prime \prime}$ de longitude oeste do Meridiano de Greenwich, limita-se pelos municípios de Granito, Serrita e Bodocó, ao Norte; Cabrobó, Orocó e Santa Maria da Boa Vista, ao Sul; Terra Nova, ao Leste e Ouricuri, a Oeste. Com altitude de 397 metros, seu relevo varia de ondulado, suave ondulado a forte ondulado. O clima da região é semiárido - quente e seco, apresentando chuvas escassas e temperatura média de $26^{\circ} \mathrm{C}$. E a vegetação característica do município é a caatinga hiperxerófila.

Para esse estudo utilizou-se duas séries históricas de precipitação pluvial, sem falhas, do posto pluviométrico 172, que correspondem aos períodos de 1919-1978 (Série 1) e 1994-2019 (Série 2). Os dados foram obtidos no site da Agência Pernambucana de Água e Clima (APAC). Os Índices de Anomalias de Chuvas (IAC) positivas e negativas para classificação de extremos foram calculados a partir das equações (1) (ROOY, 1965):

Em que:

$$
I A C=3\left[\frac{(N-\bar{N})}{(\bar{M}-\bar{N})}\right] \text { e } I A C=-3\left[\frac{(N-\bar{N})}{(\overline{\bar{X}-\bar{N})}}\right] .
$$

$N$ é a precipitação anual atual $(\mathrm{mm})$;

$\bar{N}$ é a precipitação média anual da série histórica $(\mathrm{mm})$;

$\bar{M}$ é a média das dez maiores precipitações anuais da série histórica $(\mathrm{mm})$;

$\bar{X}$ é a média das dez menores precipitações anuais da série histórica $(\mathrm{mm})$.

Anomalias positivas apresentam valores acima da média e as negativas abaixo da média. Os valores obtidos de IAC foram analisados de acordo com uma nova classificação de anos secos e úmidos proposta por Araújo et al. (2009(a)). Na Tabela 1 verifica-se as classes de intensidade IAC para o município de Parnamirim. 
RODRIGUES, ACF; RODRIGUES, ESR; SILVA, CWG; GALVÃO, SRS

Classificação da precipitação pluviométrica anual para o município de Parnamirim - PE utilizando índice de Anomalia de Chuva (IAC)

Tabela 1 - Classes do Índice de Anomalias de Chuva (IAC).

\begin{tabular}{c|c}
\hline Faixa do IAC & Classe de Intensidade \\
\hline$>4$ & Extremamente Úmido (EU) \\
2 a 4 & Muito Úmido (MU) \\
0 a 2 & Úmido (U) \\
0 a -2 & Seco (S) \\
-2 a -4 & Muito Seco (MS) \\
$<-4$ & Extremamente Seco (ES)
\end{tabular}

Fonte Adaptada: ARAÚJO et al., 2009(b).

Os dados foram organizados, processados e tabulados utilizando o editor de planilhas eletrônicas do Microsoft Excel para calcular o IAC dos anos das séries 1 e 2, obter gráficos das precipitações pluviométricas e agrupar os dados de chuvas anuais em intervalos de classes.

\section{Resultados e discussão}

A análise do comportamento das chuvas se torna importante uma vez que possibilita detectar tendências ou alterações no clima, em escalas locais, regionais, estaduais, nacionais e continentais (MARCUZZO E GOULARTE, 2012). Considerando as médias mensais de chuvas ocorridas no período das séries 1 e 2, as Figuras $1 \mathrm{~A}$ e $1 \mathrm{~B}$ apresentam os pluviogramas do município de Parnamirim-PE para os respectivos períodos estudados.

Figura 1: Média mensal de precipitação e média entre os meses das séries históricas 1 e 2 , no município de Parnamirim - PE.
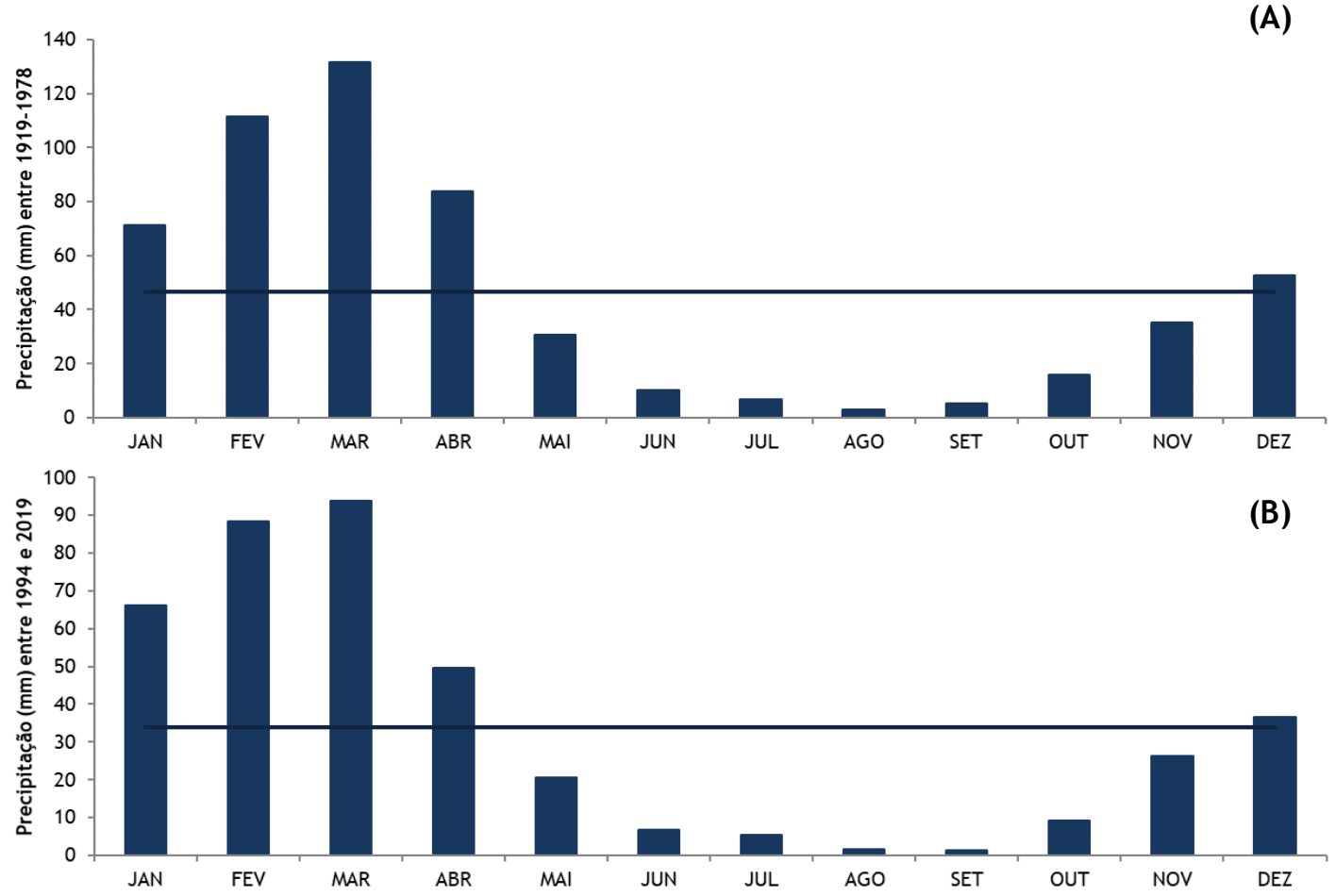

Fonte: Pesquisa direta. 
Observa-se que de dezembro a abril se encontram as maiores contribuições de chuvas para o município, o que corresponde a aproximadamente $81 \%$ e $82 \%$ das chuvas anuais das respectivas séries.

Entre os meses de maio a novembro verificam-se as menores chuvas locais, compreendendo assim, ao período de estiagem. Resultado semelhante fora obtido por Medeiros et al (2015), estudando uma série histórica de 30 anos para o estado da Paraíba, onde observaram que o período chuvoso no sertão paraibano compreende entre os meses de janeiro a abril, sendo março o mês que ocorre às pluviometrias mais elevadas, assim como, verificaram que no mês de dezembro começam as primeiras chuvas na região, que é conhecido como pré-estação chuvosa (chuvas que antecedem o iniciam do período chuvoso).

Para a série 1 os valores das chuvas anuais variaram entre o mínimo de $240,7 \mathrm{~mm}$ para o ano de 1939 e o máximo de 1055,1 mm para 1924, classificados respectivamente como muito seco e extremamente úmido. Já para a série 2 as chuvas variaram entre o mínimo de 129,7 mm para o ano de 1998 e o máximo de $698,9 \mathrm{~mm}$ para 1997, classificados respectivamente como extremamente seco e extremamente úmido.

Com os padrões climáticos de umidade das séries históricas (Figuras 2A e 2B), verificou-se que na série $1,53 \%$ das ocorrências das chuvas ao longo dos anos compreendem a períodos abaixo da média de 557,94 mm, caracterizados por anomalias negativas (S e MS). E os $47 \%$ restantes, caracterizados por chuvas acima da média histórica, que correspondem a anomalias positivas (U, MU e EU). No tocante à série 2, 54\% das ocorrências correspondem a períodos abaixo da média de 405,34 $\mathrm{mm}$, caracterizados por anomalias negativas (S, MS e ES) e $46 \%$ caracterizados por chuvas acima da média histórica, que correspondem a anomalias positivas (U, MU e EU).

Figura 2: Média percentual de padrões climáticos de umidade das séries históricas 1 e 2, observadas no município de Parnamirim-PE.
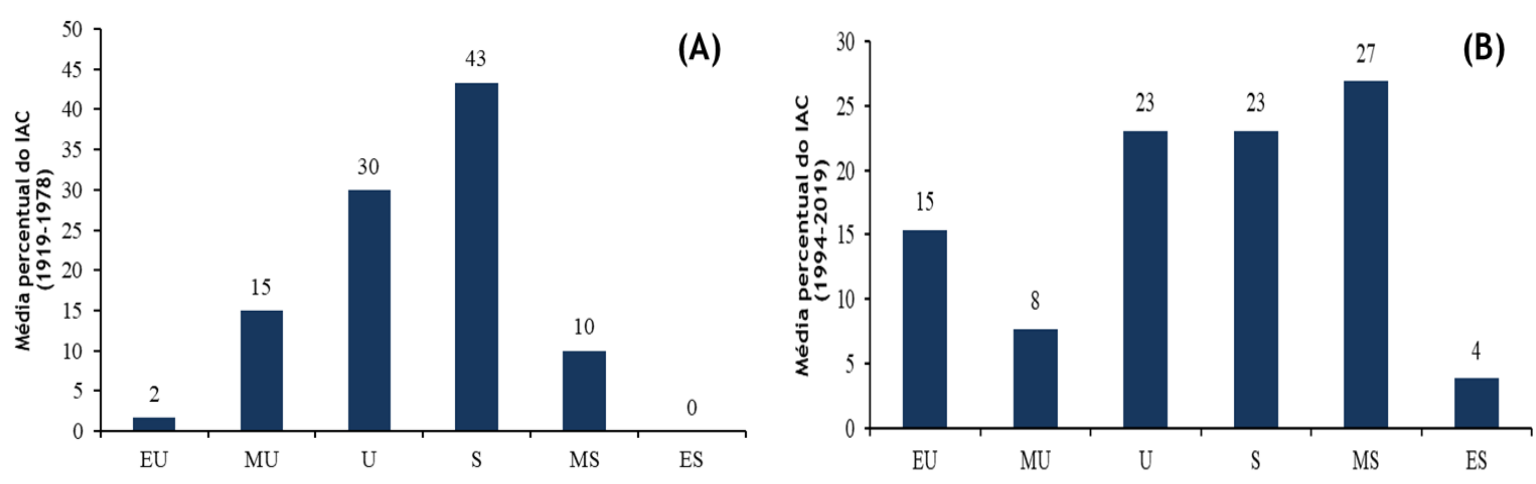

Fonte: Pesquisa direta.

De acordo com a Figura 2A, os anos secos, $43 \%$ da série 1 de Parnamirim, expressam os valores de chuvas inseridos num total de 26 anos. Os úmidos (30\%) correspondem a 18 anos, seguido de $15 \%$ de anos muito úmidos, que compreende 9 anos. Os anos com classe de intensidade muito seco (10\%), representam 6 anos da série e extremamente úmido, apenas 1 ano, expresso por 2\% do total. Das 
RODRIGUES, ACF; RODRIGUES, ESR; SILVA, CWG; GALVÃO, SRS

Classificação da precipitação pluviométrica anual para o município de Parnamirim - PE utilizando Índice de Anomalia de Chuva (IAC)

chuvas anuais analisadas, não se observou valores que se enquadrasse na classe de intensidade extremamente seco.

Na série 2 (Figura 2B), os anos com classe de intensidade muito seco, representam 7 anos da série (27\%). Os anos secos e úmidos apresentam $23 \%$ da média percentual do IAC, bem como, expressam 6 anos de ocorrência de chuvas, cada classe. Para as classes extremamente úmidos e muito úmidos, observa-se um percentual de $15 \%$ e $8 \%$, representados por 4 e 2 anos, respectivamente. Diferente da série 1, a série 2 apresenta 1 ano na classe extremamente seco, expresso por $4 \%$ do total.

O Índice de Anomalias de Chuvas (IAC) é um indicador climático da variabilidade pluviométrica e tem se revelado uma importante ferramenta de análise das precipitações considerando-se sua simplicidade procedimental e a determinação qualitativa de anomalias extremas (SANCHES et al., 2014). Assim, utilizando os resultados obtidos a partir da Equação 1, verifica-se anomalias negativas e positivas variando entre valores de $-2,8$ a 4,5 na série 1 e valores de $-5,0$ a 5,3 na série 2 (Figuras 3A e $3 \mathrm{~B})$.

Figura 3: Índices de Anomalias de Chuvas, correspondente as séries 1 e 2 no município de ParnamirimPE.
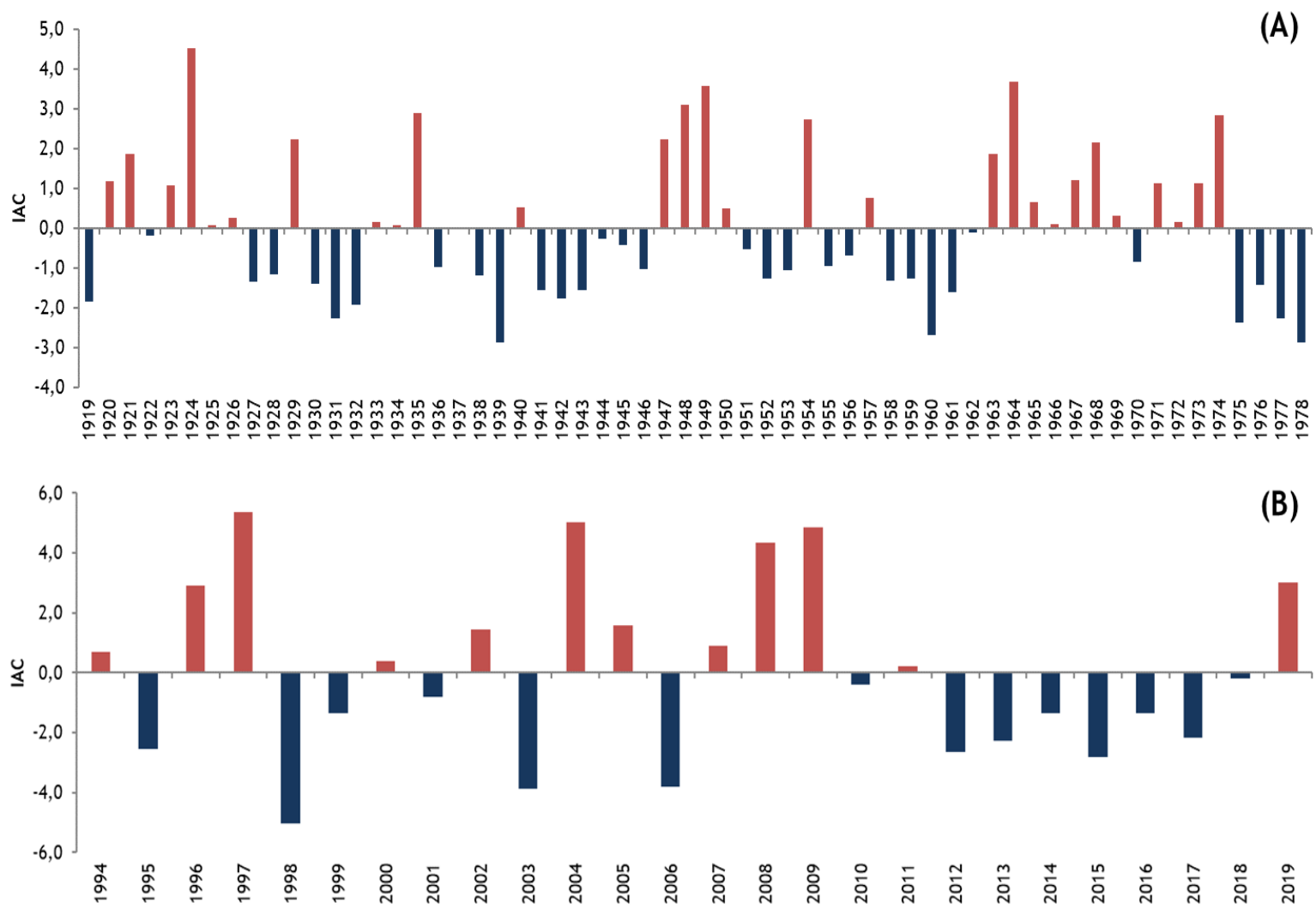

Fonte: Pesquisa direta.

De acordo com as anomalias apresentadas na Figura 3A, entre 1921 e 1926 ocorreram anos chuvosos (anomalias positivas), interrompidos em 1922 por um ano seco, com chuva anual de 536,4 
RODRIGUES, ACF; RODRIGUES, ESR; SILVA, CWG; GALVÃO, SRS

Classificação da precipitação pluviométrica anual para o município de Parnamirim - PE utilizando Índice de Anomalia de Chuva (IAC)

mm. Nesse período, ocorreu em 1924 um total de chuvas de 1055,1 mm classificado como extremamente úmido.

A série de chuvas indica que o município de Parnamirim passou por longos períodos de estiagem entre 1936 e 1946, com exceção para o ano de 1940 que foi classificado como úmido, apresentando um total de $615,5 \mathrm{~mm}$.

Entre 1951 e 1962, ocorreu mais um período de estiagem, apenas com interrupção em 1954 e 1957, que foram chuvosos, e entre 1963 e 1969 ocorreram anos chuvosos, classificados em muito úmidos (1964 e 1968) e úmidos (1963, 1965, 1966, 1967 e 1969), seguidos de um ano seco (1970) e consecutivos anos chuvosos, úmidos (1971 a 1973) e muito úmido (1974).

A série 2 (Figura 3B), entre o período de 1994 e 2011, apresenta oscilação de anos chuvosos (úmidos, muito úmidos e extremamente úmidos) e de estiagem (secos, muito secos e extremamente secos). Destaca-se o ano de 1997 pela maior lâmina de chuva da série, de valor 698,9 mm (extremamente úmido) e o ano seguinte (1998) com a menor lâmina de chuva $(129,7 \mathrm{~mm}$, extremamente seco) observada na série histórica.

Na Figura 3B, observa-se que outro longo período de estiagem ocorreu na região entre 2012 e 2018, com precipitações anuais que variaram entre o valor mínimo de 249,6 mm (2015) e o máximo de 394,8 mm (2018).

Análises que envolvam estudos de precipitação são de suma importância para o bom desempenho de várias atividades, tais como: manejo de sistemas agropecuários, conservação de recursos naturais, dimensionamento de sistemas de escoamento em conglomerados urbanos, etc (RAMOS et al., 2011). As Figuras 4A e 4B apresentam a distribuição das chuvas anuais acumuladas das séries 1 e 2 para o município de Parnamirim.

Figura 4: Distribuição das precipitações pluviométricas ocorridas entre os anos das séries 1 e 2, na cidade de Parnamirim-PE.
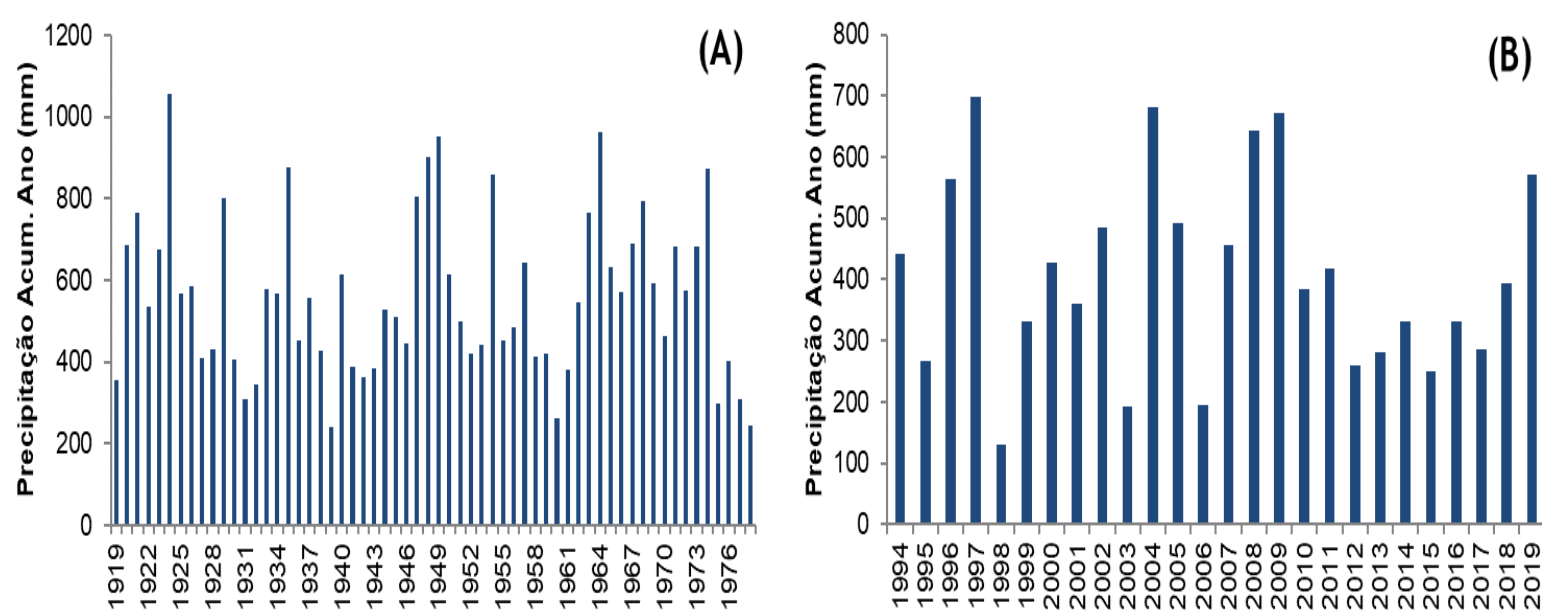

Fonte: Pesquisa direta. 
RODRIGUES, ACF; RODRIGUES, ESR; SILVA, CWG; GALVÃO, SRS

Classificação da precipitação pluviométrica anual para o município de Parnamirim - PE utilizando Índice de Anomalia de Chuva (IAC)

Verifica-se que há grande variação entre as contribuições pluviométricas ao longo dos anos das duas séries históricas, ocorrendo na série 1 a maior contribuição $(1055,1 \mathrm{~mm}$ em 1924) e a menor contribuição na série 2 (129,7 mm em 1998).

\section{Conclusões}

As séries históricas utilizadas nesse estudo indicam que aproximadamente $81 \%$ (série 1) e $82 \%$ (série 2) das chuvas anuais ocorridas no município de Parnamirim-PE, concentram-se nos meses de dezembro a abril.

O IAC calculado para eventos de precipitação pluviométrica no município se mostrou eficiente na classificação de eventos extremos, indicando que a região passou por três longos períodos de estiagem, entre 1936-1946 e 1951-1962 (série 1), e entre 2012 e 2018 (série 2).

A classe de intensidade seco ocorreu com maior frequência na série 1 e a classe muito seco predominou na série 2, confirmando que o município de Parnamirim-PE passa por vários períodos de estiagem. Entretanto, nas duas séries, os anos úmidos são recorrentes.

Tratando-se de uma cidade inserida em clima semiárido, Parnamirim possui uma pluviosidade extremamente irregular, em que a precipitação anual varia fortemente ao longo dos anos. Sendo a variabilidade da precipitação a principal característica do regime de chuvas na região do sertão pernambucano.

Este trabalho foi de suma importância para o conhecimento referente aos métodos e análises utilizados na classificação da precipitação pluviométrica do município de Parnamirim-PE, a partir dos resultados obtidas com base nos IACs.

\section{Referências}

ALVES, J. O.; PEREIRA, P. C.; QUEIROZ, M. G.; SILVA, T. G. F.; FERREIRA, J. M. S.; ARAÚJO JÚNIOR, G. $\mathrm{N}$. Índice de anomalia de chuva para diferentes mesorregiões do estado de Pernambuco. Pensar Acadêmico, Manhuaçu, v. 14, n. 1, p. 37-47, jan/jun, 2016.

ARAÚJO, L.E.; MORAES NETO, J.M.; SOUSA, F.A.S. Classificação da precipitação anual e da quadra chuvosa da Bacia do rio Paraíba utilizando o Índice de Anomalia de Chuva (IAC). Revista Ambiente \& Água, Taubaté, v. 4, p. 93-100, 2009(a).

ARAÚJO, L. E.; MORAES NETO, J. M.; SOUSA, F. A. S. Análise Climática da Bacia do Rio Paraíba - Índice de Anomalia de Chuva (IAC). Revista Engenharia Ambiental, v. 6, n. 3, p.508-523, 2009(b).

ASSIS, F. N.; ARRUDA, H. V. e PEREIRA, A. R. Aplicações de estatística à climatologia: teoria e prática. Pelotas, RS, Ed. Universitária/UFPEL, 161p, 1996. 
RODRIGUES, ACF; RODRIGUES, ESR; SILVA, CWG; GALVÃO, SRS

Classificação da precipitação pluviométrica anual para o município de Parnamirim - PE utilizando Índice de Anomalia de Chuva (IAC)

ELI, K; PITZ, J. W., NEVES, L. O.; HAVEROTH, R.; OLIVEIRA, E. C. Análise da distribuição da frequência de precipitação em diferentes intervalos de classes para Rio do Sul/SC. Enciclopédia biosfera, Centro Científico Conhecer - Goiânia, v.9, n.16, p. 106, 2013.

GURJÃO, C. D. S.; CORREIA, M. F.; CHAVES FILHO, J. B. ; ARAGAO, M. R. S. Influência do Enos (El NiñoOscilação Sul) no Regime Hidrológico do Rio São Francisco: uma Análise em Regiões com Fortes Pressões Antrópicas. Revista Brasileira de Geografia Física, Recife, v. 4, p. 774-790, 2012.

MARCUZZO, F. F. N.; GOULARTE, E. R. P. Índice de Anomalia de Chuvas do Estado do Tocantins. Geoambiente On-line, v. 19, p. 55-71, 2012. Disponível em: <http://revistas.ufg.emnuvens.com.br/geoambiente/article/view/26056/15027>. Acesso em: 20 fev. 2016.

MEDEIROS, R. M.; FRANCISCO, P. R. M.; MATOS, R. M.; SANTOS, D.; SABOYA, L. M. F. Diagnósticos das flutuações pluviométricas no Estado da Paraíba. Revista Brasileira de Geografia Física, Recife, v. 8, n. 4, p. 1017-1027, 2015.

NUNES, M. C. M.; NEVES, S. M. A. S.; NEVES, R. J.; NERY, J. T. Comportamento da precipitação pluvial no município de Cáceres Pantanal Mato-Grossense no período de 1971 a 2011. Científica, Jaboticabal, v. 44, n. 3, p. 271-278, 2016.

RAMOS, H. E. A.; SILVA, J. G. F.; IGREJA, G. C.; FREITAS, R. A.; SILVA, A. O. Análise da frequência da precipitação diária no município de Conceição do Castelo - ES. XVII Congresso Brasileiro de Agrometeorologia, Guarapari, MG. Anais. Guarapari, 2011.

ROOY, M. P. Van. A Rainfall Anomaly Index Independent of Time and Space. Notes, 14, 43, 1965.

SANCHES, F. O.; VERDUM, R.; FISCH, G. O Índice de Anomalia de Chuva (IAC) na avaliação das precipitações anuais em Alegrete/RS (1928-2009). Caminhos de Geografia (UFU), Uberlândia, v. 15, n. 51, p. 73-84, set. 2014. Disponível em: http://www.seer.ufu.br/index.php/caminhosdegeografia/article/view/26423/15462. Acesso em: 22 mar. 2016.

SANTOS, A. P. P.; ARAGÃO, M. R. S.; CORREIA, M. F.; SANTOS, S. R. Q.; SILVA, F. D. S.; ARAÚJO, H. A. Precipitação na cidade de Salvador: variabilidade temporal e classificação em quantis. Revista Brasileira de Meteorologia, v. 31, n. 4, 454-467, 2016.

SPECIAN, V. e VECCHIA, F. A. S. Distribuição da frequência mensal da precipitação para região Oeste de Goiás: comparação entre dois postos pluviométricos. Revista Ateliê Geográfico, Goiânia, v. 8, n. 1, p.200-214, abr. 2014. 
RODRIGUES, ACF; RODRIGUES, ESR; SILVA, CWG; GALVÃO, SRS

Classificação da precipitação pluviométrica anual para o município de Parnamirim - PE utilizando Índice de Anomalia de Chuva (IAC)

XAVIER, R. A. e DORNELLAS, P. C. Análise do comportamento das chuvas no município de Arapiraca, região agreste e Alagoas. Revista Geografia, Londrina, v. 14, n. 2, jul./dez. 2005. 